\section{(6) OPEN ACCESS} and Kinesiology, University of Salzburg, Hallein-Rif, Austria ${ }^{2}$ Department of Biomedical Physiology and Kinesiology, Simon Fraser University, Burnaby, Canada

\section{Correspondence to}

Jörg Spörri,

Department of Sport Science and Kinesiology, University of Salzburg, Schlossallee 49, 5400 Hallein-Rif, Austria; joerg.spoerri@sbg.ac.at

Received 9 February 2012 Accepted 4 July 2012

Published Online First

9 August 2012

\title{
Perceived key injury risk factors in World Cup alpine ski racing -an explorative qualitative study with expert stakeholders
}

\author{
Jörg Spörri, ${ }^{1}$ Josef Kröll, ${ }^{1}$ Günter Amesberger, ${ }^{1}$ Ollie M Blake, ${ }^{2}$ Erich Müller ${ }^{1}$
}

\begin{abstract}
Background There is limited knowledge about key injury risk factors in alpine ski racing, particularly for World Cup (WC) athletes.

Objective This study was undertaken to compile and explore perceived intrinsic and extrinsic risk factors for severe injuries in WC alpine ski racing.

Methods Qualitative study. Interviews were conducted with 61 expert stakeholders of the WC ski racing community. Experts' statements were collected, paraphrased and loaded into a database with inductively derived risk factor categories (Risk Factor Analysis). At the end of the interviews, experts were asked to name those risk factors they believed to have a high potential impact on injury risk and to rank them according to their priority of impact (Risk Factor Rating)

Results In total, 32 perceived risk factors categories were derived from the interviews within the basic categories Athlete, Course, Equipment and Snow. Regarding their perceived impact on injury risk, the experts' top five categories were: system ski, binding, plate and boot; changing snow conditions; physical aspects of the athletes; speed and course setting aspects and speed in general.
\end{abstract}

Conclusions Severe injuries in WC alpine ski racing can have various causes. This study compiled a list of perceived intrinsic and extrinsic risk factors and explored those factors with the highest believed impact on injury risk. Hence, by using more detailed hypotheses derived from this explorative study, further studies should verify the plausibility of these factors as true risk factors for severe injuries in WC alpine ski racing.

\section{INTRODUCTION}

World Cup (WC) alpine ski racing is known as a high-risk sport. ${ }^{1-3}$ Injury rates over the WC seasons 2006/2007 and 2007/2008 were found to be 36.7 per 100 athletes, which was alarmingly high. ${ }^{1}$ Slightly over $30 \%$ of all recorded injuries were severe ( $>28$ days of absence). ${ }^{1}$ Severe injuries may hinder the athlete from returning to the sport and they also may increase the risk of reinjury. ${ }^{4}$ Moreover, long-term adverse health effects are possible, such as a higher prevalence of early osteoarthritis. ${ }^{4}$

To be able to develop effective prevention strategies for these injuries, a comprehensive model for injury causation should be used..$^{5}$ Such a model should account for all the factors involved (figure 1): the intrinsic and extrinsic risk factors, as well as a precise description of the inciting event (injury situation and injury mechanism). ${ }^{5}$ Regarding anterior cruciate ligament injuries, the dominant injury type in WC alpine ski racing, ${ }^{1}$ recent studies provided a deeper understanding of the injury mechanisms. ${ }^{7-9}$ Furthermore, the skiing situation leading to these injuries has been described based on experts' visual analyses. ${ }^{10}$ On the basis of these analyses, athletes' technical mistakes, inappropriate tactical choices, visibility and snow conditions were suggested to be the main contributors leading up to injury situations. ${ }^{10}$ However, the factors that make the athletes predisposed and susceptible to injuries (intrinsic and extrinsic risk factors) are rather unclear for WC alpine ski racing. These factors may be completely different than the risk factors for recreational skiing. ${ }^{11-14}$ This said, knowing the factors that make the athletes predisposed and susceptible to injuries is essential for their prevention. ${ }^{5} 6$

Recently, significant changes to many aspects of WC ski racing have occurred; the introduction of carving skis and water-injected slopes being two of the most prominent. ${ }^{15} 16$ As a consequence of these changes, the course settings and the athlete's technique and physical preparation changed as well. ${ }^{17-19}$ These numerous changes have added to the complexity of the injury problem. This makes it difficult to determine the key risk factors for severe injuries based on retrospective study designs. Moreover, prospective designs are currently limited by the lack of detailed hypotheses about potential key risk factors. Therefore, a qualitative interview approach with expert stakeholders of the WC ski racing community was chosen for this study. The aim of this explorative study is to compile a list of perceived intrinsic and extrinsic risk factors for severe injuries in alpine WC ski racing. Furthermore, it is to derive precise qualitative statements about those factors that are thought to have the highest impact on injury risk in order to provide more detailed hypotheses for further studies.

\section{METHODS}

\section{Interview participants}

The analysis involved individual interviews with representatives from different expert stakeholder groups (table 1). The participation on the study was voluntary. The sampling was chosen based on the principle of maximal variation of perspectives and was enlarged as long as new perspectives were obtained. $^{20}$ However, compared to WC coaches, WC athletes, males in particular, demonstrated lower interest for participating in the interview process. Therefore, the gender-specific perspectives were unbalanced within the expert group 'WC athletes' (female: $\mathrm{n}=7$, male: $\mathrm{n}=4$ ). 


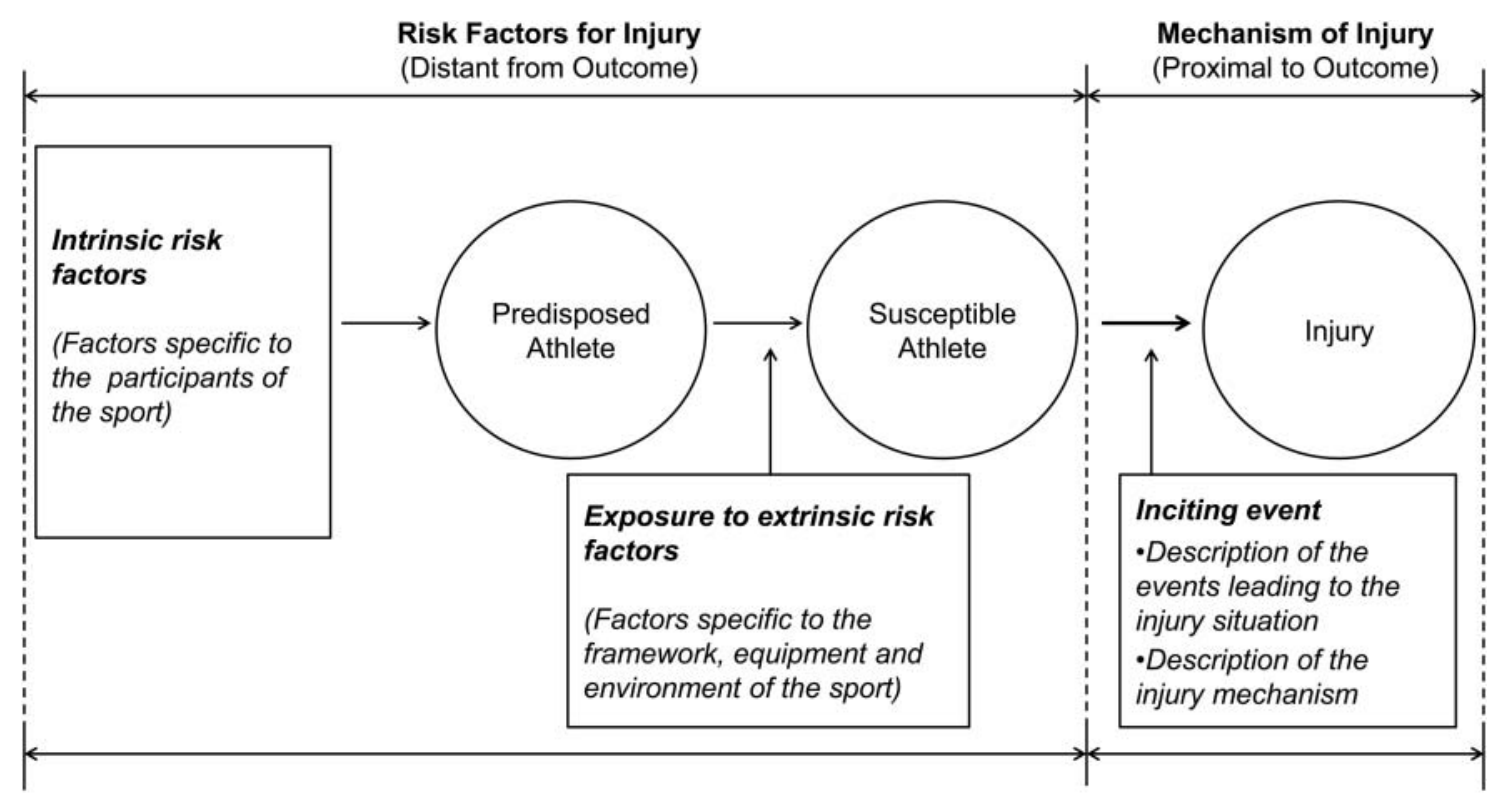

Figure 1 Model for injury causation (adapted from Meeuwisse and Bahr et al). ${ }^{56}$

\section{Interview collection}

The individual interviews took place in 2010, with two concentrated phases during the WC events in Kvitfjell and the WC finals in Garmisch. Each Interview lasted 40-70 min and was conducted by a native speaker in either German or English. All interviews were recorded using a digital voice recorder (Olympus VN-6800PC; Olympus Corporation, Tokyo, Japan) to ensure accuracy in analysis. The interviews were semistructured with prepared questions; however, certain areas were examined through improvisation based on the responses of the interviewee, ${ }^{20-22}$ with each interview ultimately covering the same material. Generally, the interviews were broken down into two parts and moved from general to specific questioning (table 2$).^{22}$

In the first part of the interview (Risk Factor AnalysisRFA), general, detailed and specific questions were posed regarding whether they saw any noticeable problems or distinct features that are related to severe injuries ( $>28$ days of absence as defined by Fuller et $a l^{23}$ ). The general section was left open to allow the interviewee the opportunity to address any area they considered to be problematic. Circular questioning was used to draw out as many ideas from the interviewees as possible with minimal influence from the interviewer. ${ }^{20}$ Each basic category (Equipment, Course Setting, Snow and Athlete) not mentioned by the interviewee in the general section was asked in the detailed section. For the specific section, a checklist with perceived risk factors was used by the interviewer to keep track of the topics covered. Any topic from this checklist not mentioned during previous questioning was asked in this section. This checklist with perceived risk factors was established through trial interviews with coaches, athletes and research team members, and was dynamically enhanced throughout the data collection process based on the interviews previously conducted. $^{20}$ In the second part of the interview (Risk Factor Rating-RFR), participants were asked to name and rank, out of all the perceived injury risk factors discussed in the

Table 1 Description of the interview participants

\begin{tabular}{|c|c|c|c|}
\hline Expert group & Inclusion criteria & Perspective & $\mathbf{n}$ \\
\hline WC coaches & Top 8 nations' WC ranking & $\begin{array}{l}\text { Head coaches }(n=8) \\
\text { Group coaches }(n=11)\end{array}$ & $\mathrm{n}=19$ \\
\hline Officials/race organisers & Responsible for WC courses & $\begin{array}{l}\text { FIS race directors }(n=5) \\
\text { TD (WC organizer) }(n=5) \\
\text { Slope engineer }(n=1)\end{array}$ & $\mathrm{n}=11$ \\
\hline Representatives ski equipment companies & Top $5 \mathrm{WC}$ ranking of ski equipment suppliers & $\begin{array}{l}\text { Head engineers }(n=5) \\
\text { Service-men }(n=5)\end{array}$ & $\mathrm{n}=10$ \\
\hline Topic specific experts & Expert with a superior specific background & $\begin{array}{l}\text { Science }(n=3) \\
\text { Expert ski equipment }(n=1) \\
\text { Expert safety equipment course }(n=1) \\
\text { Expert snow preparation }(n=1) \\
\text { Expert physical training }(n=1) \\
\text { Expert youth ski racing }(n=1) \\
\text { Disabled former WC athlete }(n=1) \\
\text { Parent of severely injured WC athlete }(n=1)\end{array}$ & $\mathrm{n}=10$ \\
\hline
\end{tabular}

FIS, International Ski Federation; TD, Technical Delegated; WC, World Cup. 
Table 2 Layout and questions for the interview process: part 1 moves from general to specific questions about distinct features or noticeable problems related to severe injuries in alpine ski racing; part 2 compiles and ranks key risk factors

General Considering severe injuries in alpine ski racing, from questions your experience and perspective can you see or do you notice any distinct features or noticeable problems?

1 Detailed In addition to the points you have mentioned, others also questions see problems in the basic categories of...(Equipment, Course Setting, Snow and Athlete-only asking about those areas not already mentioned). Considering this area and severe injuries in alpine ski racing, from your experience and perspective can you see or do you notice any distinct features or noticeable problems?

Specific If we return again to the area of ... (Equipment, Course questions Setting, Snow and Athlete)... often the points... (asking about specific aspects of each area listed in the checklist and only asking about those specific areas not already mentioned)... are mentioned

Considering this area and severe injuries in alpine ski racing, from your experience and perspective can you see or do you notice any distinct features or noticeable problems?

Ratings We have been talking about a variety of aspects relating to severe injuries in alpine ski racing. If you think about your previous statements, what do you consider the key risk factors and how would your rank them?

RFA, risk factor analysis; RFR, risk factor rating.

interview, the factors they believed had high potential impacts on the risk of severe injuries.

\section{Interview analysis}

Risk Factor Analysis

The RFA sections of the interviews were processed with methods of qualitative research ${ }^{20}{ }^{21}$ by native speakers in either German or English. At the beginning of the process, 15 audiotaped interviews, which were randomly chosen within the expert groups, were fully transcribed word for word based on common transcription rules. Thereafter, a process of reduction was used to take the full transcripts and create concise summaries of the statements (paraphrasing). ${ }^{20}$ The paraphrased statements, in either German or English, were then separated into basic categories, as well as three subcategory levels based on their similarities and their distinctions. Finally, the coded statements were entered into a digital database in their particular categories (named in English). Later, during the evaluation process, paraphrased statements from the remaining 46 interviews were extracted from the audio files without full transcriptions and were entered into the database. The categories of the database were dynamically enhanced during the analysis process based on the statements, as long as new perspectives were obtained. ${ }^{20}$

\section{Risk Factor Rating}

For the RFR section of the interview, in principal, the same data processing as for the RFA section was performed (audio file $\rightarrow$ transcription $\rightarrow$ paraphrasing) and paraphrased statements were entered into categories of the same name. For this analysis all 61 interviews were considered. In the RFR section, the interviewees were asked to select, out of all mentioned risk factors, the ones with high potential impact on injury risk, and to rank them in order of their perceived priority. All interviewees identified between one and six risk factors believed to have high impact on injury risk, whereby the majority named two or three factors. Depending on which impact on injury risk the interviewee assigned each perceived key risk factor, a ranking number was given to each statement. A lower ranking number means a higher potential impact of the risk factor, with ranking number ' 1 ' given to the highest impact. For each perceived key risk factor that was named in the RFR section, the frequency of mention and the mean of the rank numbers given by the experts were analysed. Then, a rank order for the frequency of mention and a rank order of the assigned mean rankings were created. Finally, based on the sum of these two rank orders, an overall ranking list of perceived key injury risk factors was defined.

\section{RESULTS}

\section{RFA-derivation of inductive categories}

The experts' perceived injury risk factor categories are presented in alphabetic order in table 3. Within the basic categories Athlete, Course, Equipment and Snow, a total of 32 risk factor categories were inductively derived from the qualitative analysis of the interviews.

\section{RFR-quantitative analysis of the categories}

The experts' priorities of perceived key injury risk factor categories regarding their potential impact on injury risk are presented in table 4. A total of 25 risk factors categories were suggested to play a key role for injury causation.

\section{RFA-qualitative content analysis of the categories}

Owing to space restrictions in this article, the results of the qualitative content analysis are only presented for the experts' top five key injury risk factors. An overview of the corresponding quote categories and example quotes are given in table 5 .

\section{DISCUSSION}

This study was undertaken to compile and explore perceived intrinsic and extrinsic injury risk factors for severe injuries in WC alpine ski racing. The inductively derived risk factor categories were presented in table 3. This list may serve as a

Table 3 Risk Factor Analysis: perceived injury risk factor categories derived from the interviews within the basic categories Athelte, Course, Equipment and Snow (in alphabetic order)

\begin{tabular}{ll}
\hline Athlete & Course \\
Aspects of body temperature & Poor visibility \\
Athlete's adaptability & Course maintenance during race \\
Athlete's crash behaviour & Course setting in general \\
Athlete's individual responsibility & Jumps \\
Athlete's race preparation & Level of course difficulty \\
Fatigue & Safety net position and spill zone \\
Genetics and anthropometry & Speed and course setting aspects \\
Physical aspects & Speed and topographic aspects \\
Psychological aspects & Speed in general \\
Preinjury aspects & Topography in general \\
Skiing technique and tactics & \\
Equipment & Snow \\
Binding/plate & Aggressive snow conditions \\
Gates (panels and poles) & Changing snow conditions \\
Protectors and helmets & Smooth snow surface \\
Racing suits & Techniques of snow preparation \\
Ski & \\
Ski boot & \\
System ski, plate, binding, boot & \\
\hline
\end{tabular}


Table 4 Risk Factor Rating (RFR): experts' priorities of perceived key injury risk factor categories regarding their potential impact on injury risk

\begin{tabular}{|c|c|c|c|c|c|c|}
\hline Perceived priority & Potential key injury risk factor & Mentions in RFR & Rank & Mean rank RFR & Rank & $\sum$ Rank points \\
\hline 2 & Changing snow conditions & 17 & 2 & 1.79 & 4 & 6 \\
\hline 4 & Physical aspects & 6 & 9 & 1.92 & 6 & 15 \\
\hline 4 & Speed in general & 11 & 4 & 2.23 & 11 & 15 \\
\hline 6 & Techniques of snow preparation & 9 & 6 & 2.28 & 12 & 18 \\
\hline 7 & Fatigue & 15 & 3 & 2.83 & 18 & 21 \\
\hline 7 & Skiing technique and tactics & 3 & 16 & 1.83 & 5 & 21 \\
\hline 10 & Athletes' race preparation & 2 & 20 & 1.75 & 3 & 23 \\
\hline 10 & Preinjury aspects & 1 & 22 & 1.00 & 1 & 23 \\
\hline 12 & Bad visibility & 3 & 16 & 2.00 & 8 & 24 \\
\hline 12 & Speed and topographic aspects & 5 & 10 & 2.60 & 14 & 24 \\
\hline 17 & Psychological aspects & 1 & 22 & 2.00 & 9 & 31 \\
\hline 17 & Racing suit & 3 & 16 & 2.67 & 15 & 31 \\
\hline 20 & Binding/plate & 5 & 10 & 3.00 & 22 & 32 \\
\hline 20 & Level of course difficulty & 1 & 22 & 2.00 & 10 & 32 \\
\hline 22 & Safety net position and spill zone & 4 & 14 & 2.88 & 19 & 33 \\
\hline 23 & Ski & 4 & 14 & 3.13 & 23 & 37 \\
\hline 23 & Ski boot & 2 & 20 & 2.75 & 17 & 37 \\
\hline 25 & Protectors and helmets & 1 & 22 & 4.50 & 25 & 47 \\
\hline
\end{tabular}

Mentions in RFR: number of subjects which mentioned a specific factor to have superior impact on injury risk (key risk factor). Mean rank RFR: mean value of the ranks given to a specific key risk factor by the experts. A low mean rank means high priority.

guideline for further studies. Regarding their perceived impact on injury risk, the experts' top five risk factor categories were: system of ski, binding, plate and boot; changing snow conditions; speed and course setting aspects; physical aspects; and, speed in general. Owing to space restrictions in this article, only these five risk factor categories are discussed in depth. In the following synopsis, the experts' direct quotes are highlighted with quote signs and italic font.

\section{System ski, binding, plate and boot}

According to the experts' rating, the 'system of ski, binding, plate and boot' is too direct in force transmission, too aggressive in the ski-snow interaction, and too difficult to get off the edge once the ski is carving. As a result, as argued by some experts, the equipment is not controllable if the athlete loses his/her balance due to its unpredictable self-dynamic behaviour. Driving factors for these equipment handling problems may be: (1) the skis' side-cut

"Less side-cut means less force and less violence in injury situations."

(2) the skis' width

"Wider skis make it harder to get up on and off the edge"

(3) the skis' length

"Longer skis are safer and you feel more comfortable at high speed runs."

(4) a homogenous bending line of the skis

"The binding plate takes partly the responsibility for today's injury frequency, since it significantly influences the bending line of the ski and causes that the ski does a less likely break-away or slides."
(5) the skis' torsional stiffness

"There is a possibility to make the skis more aggressive by changing the torsional stiffness"

and (6) the weight of the whole equipment system

"... if this mass once is accelerated, it can lead to an uncontrolled self-dynamic behaviour of the equipment."

Furthermore, stiff boots and high standing heights are believed to play a central role for injuries

"Boots are too stiff...especially at low temperatures boots get very direct regarding force transmission."

"Standing high plays a central role, which must be reduced Nowadays, unhealthy lever arms result in high forces which act on the body."

All suggested driving factors are plausible and are in line with the mechanical theory of skiing. ${ }^{24-27}$ Furthermore, both high standing heights and strong side-cuts of the skis have been suggested to favour a sudden catch of the edge while skiing, ${ }^{15}$ which is a crucial factor leading up to the injury mechanisms specific for WC alpine ski racing.

\section{Changing snow conditions}

Widely discussed among the ski racing community, changing snow conditions, in particular within one run, requires great effort for the athlete to adapt immediately and it is difficult to set up and prepare the equipment for all different conditions. Generally, injected snow and icy conditions are believed to be safer than aggressive snow conditions. 
Table 5 Qualitative content analysis: generalised quote categories and example quotes of the top five perceived injury risk factor categories derived from the interviews

\begin{tabular}{|c|c|}
\hline Risk factor and quote categories & Example quotes \\
\hline \multicolumn{2}{|l|}{ System ski, plate, binding, boot } \\
\hline System is too aggressive in ski-snow interaction & $\begin{array}{l}\text { "The system ski, boot, binding, plate is too aggressive and there should be more } \\
\text { room for mistakes" }\end{array}$ \\
\hline System is too direct in force transmission to the body & $\begin{array}{l}\text { "It is always tried to make the force transmission more direct ... but this } \\
\text { development could go at the expense of safety" }\end{array}$ \\
\hline System is difficult to control & $\begin{array}{l}\text { "It happens often, that if you lose the grip on the outer ski the inner ski catches the } \\
\text { edge and catapults you out of the turn" }\end{array}$ \\
\hline System has a strong self-dynamic/self-steering behaviour & $\begin{array}{l}\text { "If the equipment is once out of control, it develops a certain self-dynamic } \\
\text { behaviour and the athlete does not get rid of the edge" }\end{array}$ \\
\hline \multicolumn{2}{|l|}{ Changing snow conditions } \\
\hline Changing conditions from run to run make it difficult for the athletes to adapt & "Every injected slope is different making it hard to have the proper equipment" \\
\hline Changing conditions within one run make it difficult for the athletes to adapt & $\begin{array}{l}\text { "A mix of injected and aggressive snow on the same slope is a problem for injury } \\
\text { as it is hard to setup the equipment for both situations" }\end{array}$ \\
\hline Changing conditions due to bib-number can be a safety problem & "Changes of the slope during the race mainly affect racers with lower levels" \\
\hline \multicolumn{2}{|l|}{ Speed and course setting aspects } \\
\hline Speed in combination with small turn radii is dangerous & $\begin{array}{l}\text { "Speed in combination with tight turns is more dangerous than a more opened turn } \\
\text { at high speed" }\end{array}$ \\
\hline Speed in combination with small turn radii leads to higher forces & "As result of the high turn speed, there are acting high external forces" \\
\hline Speed in turns is higher today than in the past & $\begin{array}{l}\text { "The increase of turn speed was in the last few years disproportionately higher } \\
\text { than the increase in athletes' strength" }\end{array}$ \\
\hline Speed can be controlled through course setting & "Speed control must be done by course setting" \\
\hline Speed control through course setting can be problematic & $\begin{array}{l}\text { "A tighter course set does not decrease the risk, since forces are increased. } \\
\text { Therefore, speed reduction by course setting is not wise" }\end{array}$ \\
\hline Speed cannot be controlled through course setting in every case & $\begin{array}{l}\text { "Speed control through tighter course setting is useless as long as the athlete is } \\
\text { still able to carve the tighter radius" }\end{array}$ \\
\hline \multicolumn{2}{|l|}{ Physical aspects } \\
\hline High fitness level is important to reduce injury risk & "Physical training is very important for athletes to avoid injuries" \\
\hline Athletes' fitness levels are not always sufficient & $\begin{array}{l}\text { "A lot of younger athletes (women in particular) don't get enough time to work on } \\
\text { their conditioning as they are selected at young age and have pressure to move up } \\
\text { in the ranks" }\end{array}$ \\
\hline Athletes' fitness levels are already at the limit and cannot be further improved & $\begin{array}{l}\text { "The physical conditioning of the human body reaches its limit earlier than the } \\
\text { equipment development" }\end{array}$ \\
\hline Forces acting on the body are too high and must be reduced & $\begin{array}{l}\text { "The forces are too high for the human body and should be reduced in reasonable } \\
\text { degree" }\end{array}$ \\
\hline Too specialised physical training is a safety problem & $\begin{array}{l}\text { "Physical training usually aims on reaching with a minimal effort a maximum for } \\
\text { the competition, so that there are reserves left" }\end{array}$ \\
\hline \multicolumn{2}{|l|}{ Speed in general } \\
\hline High speed increases the 'destructive potential' of the energy involved & "Crashes at high speed lead more frequently to injuries than crashes at low speed" \\
\hline Constantly high speed over a long sector is a injury risk factor & $\begin{array}{l}\text { "The factor speed is a huge problem, especially a constantly high speed, which } \\
\text { deceives the senses" }\end{array}$ \\
\hline Speed in general should be lowered for safety reasons & "A speed reduction of $20-30 \mathrm{~km} / \mathrm{h}$ would make sense" \\
\hline
\end{tabular}

"Icy snow conditions are safer than aggressive snow, because the equipment does not react as fast"

Moreover, according to some experts, snow injection reduces the changes due to bib number (traces) and, therefore, may increase safety. However, partial injection is suggested to be problematic since it changes the mechanical proprieties of the snow, ${ }^{16}$ and the equipment is set up and prepared for the iciest part. Consequently, the ski-snow interaction is too direct in force transmission when entering a section with 'grippy' artificial snow

"If on a slope with aggressive snow only a couple of turns are injected, the setup must be tuned in a manner that allows skiing on ice...in doing so the set-up gets too aggressive in sections without ice."

Hence, the influence of the slope preparation and maintenance on the ski-snow interaction seems to be an important key for a better understanding of injuries in WC alpine ski racing. ${ }^{7} 10$

\section{Speed and course setting aspects}

According to the experts, in carved turns speed in combination with small turn radii leads to high forces on the body. This is theoretically plausible and coincides with the literature. ${ }^{15}{ }^{25}$ Generally, some experts feel that speed in turns has increased in the last years

"The big difference today with the carving skis is that you do not loose so much speed through a turn making it more risky for injuries."

Typically, the reduction or control of speed in turns is attempted by course settings that turn more out of the direction of the fall line. However, according to the experts, this is not the key for risk reduction in every case. As long as the turn still can be carved and more skidding is not provoked, speed control by course setting may not be very effective; rather, higher forces may occur due to smaller turn radii at a similar speed. An alternative approach may be course settings that 
locally slow down the racers in a substantial manner before key sections

$$
\begin{aligned}
& \text { "...it should be given more importance to tactical aspects, so that } \\
& \text { the athlete really has to decide where to slow down and to pass } \\
& \text { with full speed." }
\end{aligned}
$$

\section{Physical aspects}

According to the experts, a superior fitness level is one of the most important perceived factors for injury prevention

"Physically weak athletes have a higher risk for injuries."

Even though the importance of a superior fitness level for injury prevention is widely accepted in practice, no definite conclusions can be made based on the existing literature. ${ }^{28}$ However, fatigue is known to have a negative impact on balance control, ${ }^{29}$ and physical fitness has an effect on reaction time during exercise. ${ }^{30}$ Therefore, it seems to be reasonable that a lack of fitness and early fatigue could be risk factors for injuries. According to the experts, there are actually two main problems in alpine WC ski racing regarding 'physical aspects' of the athletes: (1) the fitness level of today's top athletes reaches physical limitation and cannot be further improved in order to resist the outer forces and (2) younger athletes, in particular women, are not always sufficiently prepared to enter the WC.

\section{Speed in general}

According to the experts, high skiing speed is a general perceived risk factor for injuries, in particular, if speed is constantly high. They argue that this deceives the senses and results in a loss of concentration. In addition, the athlete may have too little time to react and/or correct if an injury situation develops rapidly at high skiing speeds. ${ }^{7}{ }^{15}$ High skiing speeds mean high kinetic energy and, as a result, can induce serious injuries in the event of a quick energy conversion during injury events or crashes

\section{"...technical mistakes do not have as fatal consequences at lower speed."}

Therefore, some experts think that speed in general should be reduced.

\section{Methodological considerations}

The qualitative approach used in this study contributes to the theoretical and conceptual body of knowledge and adds new perspectives regarding perceived injury risk factors in alpine ski racing. However, there are some dangers/limitations related to the study design used.

First, the applied study design does not allow for verification of whether the perceived injury risk factors are true risk factors. These factors primarily need to be validated against formal aetiological studies in order to confirm their status as injury risk factors.

Second, the quality of results depends on the quality of the interviews, as well as on the expertise and degree of reflection of the interviewees. Therefore, it was attempted to provide a comfortable environment in which to conduct the interviews, and each individual interview started with an open-ended question in order to encourage the interviewee to speak freely. ${ }^{20}$ In order to maximise the richness of data, the sample was chosen in an attempt to maximise the variation of expertise and perspectives. ${ }^{20}$ However, due to the voluntary character of this study, some limitations remain with respect to an unbalanced sampling, especially, for the quantitative analysis of the interviews.

Third, the qualitative interview approach includes the danger of subjectivity. Therefore, three different researchers were involved in conducting and analysing the interviews: (1) the first five interviews were conducted and processed by all three researchers together and (2) for all interviews, the classification of the paraphrased statements into risk factor categories was performed by all researchers together in a permanent exchange of perspectives.

Fourth, the results were not stratified by discipline. This may limit the representation of the findings for specific disciplines since the perceived risk factors and, in particular, their perceived priority, may be different.

\section{CONCLUSION}

As shown in this paper, injuries in WC alpine ski racing can have various intrinsic and extrinsic risk factors. In order to decrease injury rates in alpine ski racing effectively, a comprehensive perspective might be needed. It is conceivable that a change of one factor alone may not improve the injury problem substantially, and several risk factors have to be approached by prevention interventions. Nevertheless, not all risk factors have the same impact on injury risk. This study compiled and explored those perceived risk factors with the highest believed impact on injury risk. Hence, further studies should verify the plausibility of these factors as true risk factors by using more detailed hypotheses derived from this explorative study.

\section{What this study adds}

- This study compiles a list of perceived intrinsic and extrinsic injury risk factors for severe injuries in World Cup alpine ski racing. This list may serve as a guideline for further studies with respect to injuries in alpine ski racing.

- This study explores those perceived risk factors with the highest believed impact on injury risk. With its qualitative character, it provides a base for more detailed hypotheses for further aetiological studies in alpine ski racing.

Acknowledgements We thank all the athletes and coaches, the ski industry, organisers, officials and topic-specific experts for their cooperation and their contributions.

Funding This study was financially supported by the International Ski Federation Injury Surveillance System. The funding source had no involvement in the study design, in the collection, analysis and interpretation data, in the writing of the report, or in the decision to submit this paper for publication.

\section{Competing Interests None}

Ethical approval This study was approved by the Ethics Committee of the Department of Sport Science and Kinesiology at the University of Salzburg.

Provenance and peer review Not commissioned; externally peer reviewed.

Data sharing statement Additional data from the digital database of the Risk Factor Analysis (RFA) of this study was presented in the unpublished 'FIS report $2010^{\prime}$ to the International Ski Federation.

\section{REFERENCES}

1. Florenes TW, Bere T, Nordsletten L, et al. Injuries among male and female World Cup alpine skiers. Br J Sports Med 2009;43:973-8. doi:10.1136/bjsm.2009.068759.

2. Ekeland A, Dimmen S, Lystad $\mathrm{H}$, et al. Completion rates and injuries in alpine races during the 1994 Olympic Winter Games. Scand J Med Sci Sports 1996:6:287-90.

3. Pujol N, Blanchi MP, Chambat P. The incidence of anterior cruciate ligament injuries among competitive Alpine skiers: a 25-year investigation. Am J Sports Med 2007:35:1070-4. doi:10.1177/0363546507301083.

4. Myklebust G, Bahr R. Return to play guidelines after anterior cruciate ligament surgery. Br J Sports Med 2005;39:127-31. doi:10.1136/bjsm.2004.010900. 
5. Bahr R, Krosshaug T. Understanding injury mechanisms: a key component of preventing injuries in sport. Br J Sports Med 2005;39:324-9. doi:10.1136/bjsm. 2005.018341.

6. Meeuwisse WH. Assessing causation in sport injury: a mulitfactorial model. Clin J Sport Med 1994:4:166-70.

7. Bere T, Florenes TW, Krosshaug T, et al. Mechanisms of anterior cruciate ligament injury in World Cup alpine skiing: a systematic video analysis of 20 cases. $A m ~ J$ Sports Med 2011:39:1421-9. doi:10.1177/0363546511405147.

8. DeMorat G, Weinhold P, Blackburn T, et al. Aggressive quadriceps loading can induce noncontact anterior cruciate ligament injury. Am J Sports Med 2004;32:477-83. doi:10.1177/0363546503258928.

9. Krosshaug T, Slauterbeck JR, Engebretsen L, et al. Biomechanical analysis of anterior cruciate ligament injury mechanisms: three-dimensional motion reconstruction from video sequences. Scand J Med Sci Sports 2007:17:508-19. doi:10.1111/j.1600-0838.2006.00558.x.

10. Bere T, Florenes TW, Krosshaug T, et al. Events leading to anterior cruciate ligament injury in World Cup Alpine Skiing: a systematic video analysis of 20 cases. $\mathrm{Br} J$ Sports Med 2011:45:1294-302. doi:10.1136/bjsports-2011-090517.

11. Hunter RE. Skiing injuries. Am J Sports Med 1999;27:381-9.

12. Bissell BT, Johnson RJ, Shafritz AB, et al. Epidemiology and risk factors of humerus fractures among skiers and snowboarders. Am J Sports Med 2008;36:1880-8. doi:10.1177/0363546508318195

13. Kirkpatrick AW, McBeth PB, Ball CG, et al. Alpine ski and snowboarding traumatic injuries: incidence, injury patterns, and risk factors for 10 years. Am J Surg 2009:197:560-4. doi:10.1016/j.amjsurg.2008.12.016.

14. Sulheim S, Holme I, Rodven A, et al. Risk factors for injuries in alpine skiing, telemark skiing and snowboarding — case-control study. Br J Sports Med 2011;45:1303-9. doi:10.1136/bjsports-2011-090407.

15. Niessen W, Müller E. Carving - biomechanische Aspekte bei der Verwendung stark taillierter Skier und erhöhter Standflächen im alpinen Skisport. Leistungssport 1999;: 1:39-44.

16. Fauve M, Rhyner HU, Schneebeli M. Preparation and maintenance of pistes- the handbook for practitioners. Davos: Swiss Federal Institute for Snow and Avalanche Research, 2002.
17. FIS. FIS International Ski Competition Rules ICR 2008. 2008; http://www.fis-ski. com/data/document/icr2008.pdf

18. Müller $\mathbf{E}$, Schwameder $\mathrm{H}$. Biomechanical aspects of new techniques in alpine skiing and ski-jumping. J Sports Sci 2003;21:679-92. doi:10.1080/ 0264041031000140284

19. Raschner C, Schiefermüller C, Zallinger G, et al. Biomechanische Analyse der Carvingtechnik als Grundlage modifizierter Trainingsmethoden in der konditionellen Vorbereitung alpiner Ski- und Skrennläufer. Spectrum 2001;13(Suppl):91-7.

20. Dicicco-Bloom B, Crabtree BF. The qualitative research interview. Med Educ 2006; 40:314-21. doi:10.1111/.1365-2929.2006.02418.x.

21. Fontana $\mathbf{A}$, Frey JH. The interview: from structered questions to negotiated text. In Denzin NK, Lincoln YS. eds. Collecting and interpreting qualitative materials. Thousand Oaks, CA: Sage Publications, 2003.

22. Myers MD, Newman M. The qualitative interview in IS research: examining the craft. Info Organ 2007:17:2-26.

23. Fuller CW, Ekstrand J, Junge $\mathrm{A}$, et al. Consensus statement on injury definitions and data collection procedures in studies of football (soccer) injuries. $\mathrm{Br} J$ Sports Med 2006; 40:193-201. doi:10.1136/bjsm.2005.025270.

24. Renshaw AA, Mote CD. A model for the turning snow ski. Int J of Mech Sci 1989;31:721-36.

25. Howe J. The new skiing mechanics. 2nd edn. Waterford: McIntire Publishing, 2001.

26. Lind D, Sanders SP. The physics of skiing — skiing at the triple point. New York: Springer Verlag, 2004

27. Mössner M, Heinrich D, Kaps $P$, et al. Effects of ski stiffness in a sequence of ski turns. In: Müller E, Lindinger S, Stöggl T. eds. Science and skiing IV. Maidenhead: Meyer \& Meyer Sport (UK) Ltd., 2009.

28. Murphy DF, Connolly DA, Beynnon BD. Risk factors for lower extremity injury: a review of the literature. Br J Sports Med 2003;37:13-29.

29. Simoneau $\mathbf{M}$, Begin $F$, Teasdale $N$. The effects of moderate fatigue on dynamic balance control and attentional demands. J Neuroeng Rehabil 2006:3:22. doi:10.1186/1743-0003-3-22.

30. Brisswalter $\mathbf{J}$, Arcelin R, Audiffren $\mathbf{M}$, et al. Influence of physical exercise on simple reaction time: effect of physical fitness. Percept Mot Skills 1997;85(Pt 1): $1019-27$. 